\title{
What Drives the North Atlantic Oscillation's Temperature Anomaly Pattern? Part I: The Growth and Decay of the Surface Air Temperature Anomalies
}

\author{
JosePh P. Clark AND STEVEN B. FELDSTEIN \\ Department of Meteorology and Atmospheric Science, The Pennsylvania State University, \\ University Park, Pennsylvania
}

(Manuscript received 7 February 2019, in final form 18 August 2019)

\begin{abstract}
Composite analysis is used to examine the physical processes that drive the growth and decay of the surface air temperature anomaly pattern associated with the North Atlantic Oscillation (NAO). Using the thermodynamic energy equation that the European Centre for Medium-Range Weather Forecasts implements in their reanalysis model, we show that advection of the climatological temperature field by the anomalous wind drives the surface air temperature anomaly pattern for both NAO phases. Diabatic processes exist in strong opposition to this temperature advection and eventually cause the surface air temperature anomalies to return to their climatological values. Specifically, over Greenland, Europe, and the United States, longwave heating/cooling opposes horizontal temperature advection while over northern Africa vertical mixing opposes horizontal temperature advection. Despite the pronounced spatial correspondence between the skin temperature and surface air temperature anomaly patterns, the physical processes that drive these two temperature anomalies associated with the NAO are found to be distinct. The skin temperature anomaly pattern is driven by downward longwave radiation whereas stated above, the surface air temperature anomaly pattern is driven by horizontal temperature advection. This implies that the surface energy budget, although a useful diagnostic tool for understanding skin temperature changes, should not be used to understand surface air temperature changes.
\end{abstract}

\section{Introduction}

The North Atlantic Oscillation (NAO) is one of the most established and dominant teleconnection patterns observed over the Northern Hemisphere (e.g., Wallace and Gutzler 1981). Characterized by a redistribution of atmospheric mass between the midlatitude and subtropical North Atlantic, and arising from the remnants of breaking of synoptic-scale Rossby waves (e.g., Benedict et al. 2004; Franzke et al. 2004; Rivière and Orlanski 2007; Woollings et al. 2008), the NAO exerts an influence on the weather and climate from subseasonal to interannual time scales.

The subseasonal changes in weather associated with the NAO occur within a 2-3-week period, which corresponds to growth and decay periods that both last about 6-12 days, and to the amount of time that it takes for the lagged autocorrelation function of the NAO to decay by a factor of $e$ (Feldstein 2000). The time period over which the NAO grows and decays can perhaps be

Corresponding author: Joseph P. Clark, juc414@psu.edu explained by the driving by preexisting synoptic-scale eddies whose self-interaction projects onto the NAO (Luo et al. 2007) or by barotropic stochastic eddy forcing (Vallis et al. 2004).

The influence that the NAO exerts on the weather and climate is primarily felt along the continents that border the North Atlantic Ocean. These impacts are wideranging and include anomalies in surface air temperature (SAT), moisture, and precipitation (e.g., van Loon and Rogers 1978) - all of which can lead to subsequent social, economic, and ecological impacts (Hurrell et al. 2003). The focus of this study is the subseasonal SAT changes that accompany the NAO.

Previous studies have surmised that the NAO's SAT anomaly pattern (pictured in Fig. 1 as a composite against the NAO events described in section 2), is driven by horizontal temperature advection (e.g., Walker and Bliss 1932; van Loon and Rogers 1978; Rogers and van Loon 1979; Wallace and Gutzler 1981; Watanabe 2004; Woollings et al. 2008). In addition to horizontal temperature advection, however, Trigo et al. (2002) note that anomalous radiative forcing (both shortwave and 

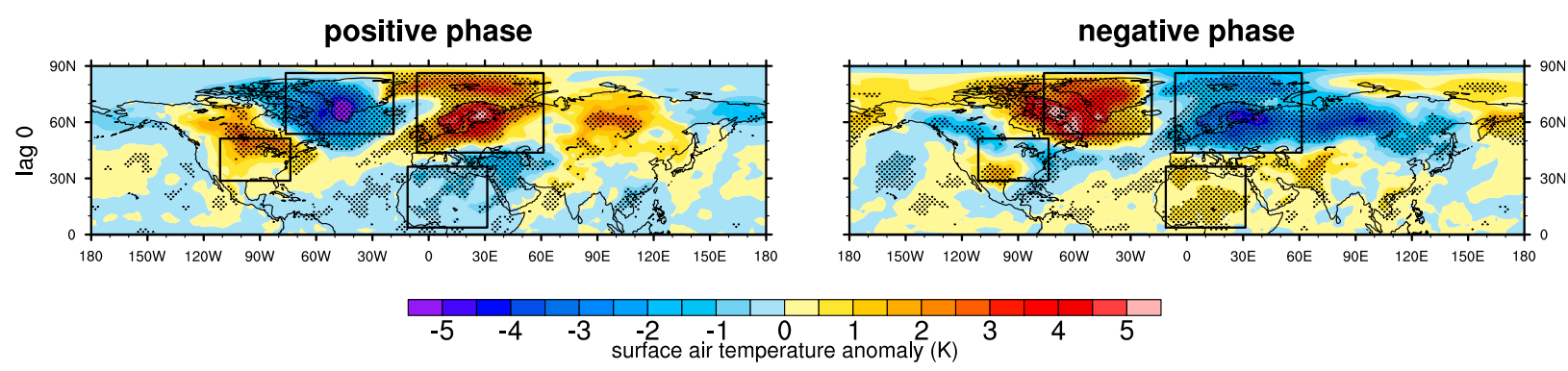

FIG. 1. Surface air temperature anomaly composite for the (left) positive and (right) negative phases of the NAO. For details on how the $\mathrm{NAO}$ is defined, see the text in section 2 associated with Fig. 2.

longwave) from clouds may also contribute to the NAO's SAT anomaly pattern. The viewpoint that horizontal temperature advection drives the NAO's SAT anomaly pattern is supported qualitatively by maps of anomalous sea level pressure, from which the implied direction of the anomalous winds relative to the climatological temperature gradient suggests the observed SAT anomaly pattern (see Fig. 1 of Wallace and Gutzler 1981). Such inferences from sea level pressure anomaly maps can also be found in the early studies of Teisserenc de Bort (1883) and Namias (1953).

Apart from the qualitative sea level pressure anomaly map argument, the spatial pattern of horizontal temperature advection associated with the NAO (specifically, the advection of the climatological temperature by the anomalous zonal wind) resembles the NAO's SAT anomaly pattern, further supporting the viewpoint that the NAO's SAT anomaly pattern is driven by horizontal temperature advection (Thompson and Wallace 2000). However, the study of Thompson and Wallace (2000) (along with many other NAO studies) utilizes monthly mean data to determine the spatial pattern of horizontal temperature advection. Since the publication of Thompson and Wallace (2000), it has become increasingly evident that the NAO grows and decays within a 2-3-week time frame (Feldstein 2000) and therefore, it is perhaps more accurate to evaluate the weather impacts of the NAO with daily data. In addition, the mechanism that causes the NAO's SAT anomalies to decay is not well established. The purpose of this study is thus to evaluate the contributions that various processes have on both the growth and decay of the daily temperature changes observed when the NAO is active.

Relative to the number of studies that examine the NAO's SAT anomalies with monthly mean data (e.g., Trigo et al. 2002), few studies have addressed the question of what drives the growth and decay of the NAO's SAT anomalies with daily data. One study that has addressed this question, Diao et al. (2015), reported findings that are somewhat different from the leading viewpoint that the NAO's SAT anomalies are driven by the advection of the climatological temperature field by the anomalous wind. After temporally filtering various terms in the thermodynamic energy equation, they showed that the NAO's SAT anomalies near Warsaw and Saint Petersburg grow in response to the advection of the submonthly (7-31-day) temperature anomalies by the submonthly wind anomalies and decay through the advection of the transient (2-7-day) temperature anomalies by the submonthly wind anomalies.

As an alternative to the thermodynamic energy equation, some studies utilize the surface energy budget to understand changes in SAT, particularly over the Arctic where over the last several decades, the SAT is increasing at a rate of about twice the global average (Polyakov et al. 2002; Serreze and Francis 2006). Although the surface energy budget applies strictly only to the skin temperature, rather than to the SAT (usually taken to be the temperature $2 \mathrm{~m}$ above the surface), the high spatial correspondence between the skin temperature and SAT (Chen et al. 2002; Gong et al. 2017; Lee et al. 2017) is often taken as justification for using the surface energy budget as a means to understand changes in SAT as well. In this study, however, we separately address the processes that contribute to skin temperature and SAT changes by analyzing not only the surface energy budget, but also the thermodynamic energy equation at the lowest level of the reanalysis model of the European Centre for Medium-Range Weather Forecasts (ECMWF; see section 2), which corresponds to a height of about $10 \mathrm{~m}$ above the surface (Berrisford et al. 2009). This lends insight into the relationship between the skin temperature and SAT and also to the extent that the surface energy budget can be applied to understand changes in SAT as well as changes in skin temperature.

An overview of the reanalysis data and methods used in this study follows in section 2, which includes a discussion of the composite method, and the thermodynamic and surface energy budget equations that are used. A description of the results follows in section 3, 
for which each term in each budget equation is analyzed and discussed. Finally, a summary is provided in section 4 .

\section{Data and methods}

For this study, daily data from the ECMWF interim reanalysis (ERA-Interim; Dee et al. 2011) on a $2.5^{\circ} \times$ $2.5^{\circ}$ grid are utilized from 1979 to 2012 with a focus on the winter months of December-February (DJF), the season in which the NAO is most active (e.g., Barnston and Livezey 1987). From all analyzed quantities, the first 10 harmonics of the calendar-day-dependent seasonal cycle is subtracted at each grid point.

Composites of these DJF anomaly fields are produced based on days in which the NAO amplitude time series, defined by the first principle component of an empirical orthogonal function (EOF) analysis (e.g., Kutzbach 1967), attains a peak value that is more than one standard deviation from its DJF mean value and is separated from all other peak values by more than 12 days. The EOF analysis is applied to DJF mean sea level pressure anomaly data for the domain $20^{\circ}-80^{\circ} \mathrm{N}, 90^{\circ} \mathrm{W}-40^{\circ} \mathrm{E}$. The 12-day time frame used to separate events corresponds to the average number of days, over each DJF season, that it takes for the lagged autocorrelation function of the NAO amplitude time series to decay by a factor of $2 e$ (see Fig. 2; interestingly, there is substantial interannual variability in this time scale). In this way, 85 positive NAO events and 75 negative NAO events are identified. For events near the beginning or the end of each DJF season, composite lags are permitted to extend into the other months.

Statistical significance is tested using a Monte Carlo approach. A total of 250 random composites with the same number of events are generated and statistical significance is marked for $p<0.10$, based on a twotailed test.

\section{a. Thermodynamic energy equation on the lowest model level}

The ECMWF reanalysis model uses a hybrid-pressure ("eta") coordinate system that is terrain following (ECMWF 2014). Data are provided at the lowest model level, which is approximately (based on the hydrostatic equation) $10 \mathrm{~m}$ above the surface (Berrisford et al. 2009). Because the temperature on the lowest eta surface has a very close correspondence with the 2-m temperature (not shown), which is typically taken to be the SAT, we analyze the data provided on this surface with the terms in the thermodynamic energy equation as implemented in the reanalysis model. This enables us to better understand the processes that contribute to temperature changes near the surface.

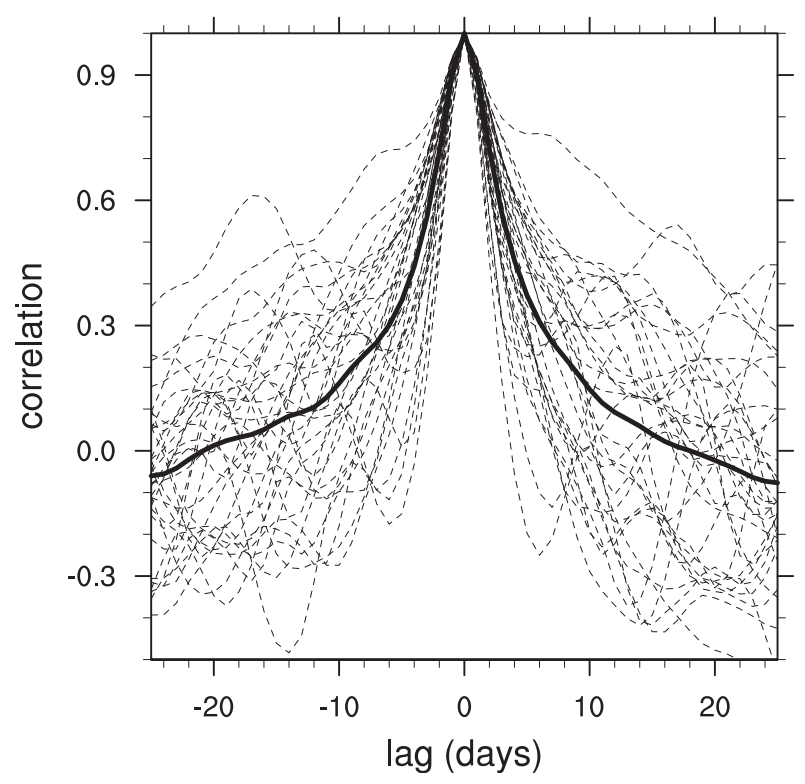

FIG. 2. The 1979-2012 December-February autocorrelation functions for the NAO amplitude time series. Dashed lines indicate the autocorrelation for different seasons. The thick line is the mean autocorrelation function.

The thermodynamic energy equation implemented in the reanalysis model can be written as

$$
\frac{\partial T}{\partial t}=-u \frac{\partial T}{\partial x}-v \frac{\partial T}{\partial y}-\dot{\eta} \frac{\partial T}{\partial \eta}+\frac{\kappa T \omega}{p}+P_{T}+\text { Res }
$$

(ECMWF 2014). This equation states that the temperature may change in response to horizontal temperature advection $-u \partial T / \partial x-v \partial T / \partial y$, vertical temperature advection $-\dot{\eta} \partial T / \partial \eta$, adiabatic warming $\kappa T \omega / p$ (where $\kappa \equiv R_{d} / c_{p d}$ ), and diabatic heating $P_{T}$, where the diabatic heating term $P_{T}$ is composed of longwave radiative heating/cooling, shortwave radiative heating/cooling, latent heat release and vertical mixing. All of these terms are either explicitly provided by ERA-Interim or may be calculated using data that are provided. The Res term is a residual accounting for the analysis increment (e.g., Trenberth et al. 2011) and for any inconsistencies between (1) and the precise equation that is implemented by ECMWF. These inconsistencies include neglect of moisture in the adiabatic term, neglect of horizontal diffusion, and differences between our numerical methods and those that the ECMWF reanalysis model uses (ECMWF 2014). For example, horizontal derivatives are evaluated using spherical harmonics. ${ }^{1}$ Details about how

\footnotetext{
${ }^{1}$ The built-in NCAR command language procedure "gradsf" is utilized.
} 
the vertical advection term is calculated are included in the appendix.

Because many studies have qualitatively attributed changes in SAT associated with the NAO to advection of the climatological temperature field by the anomalous wind (e.g., Wallace and Gutzler 1981, their Fig. 1), we divide the advection term into components by letting $\mathbf{u}=\overline{\mathbf{u}}+\mathbf{u}^{\prime}$ and $T=\bar{T}+T^{\prime}$,

$-\mathbf{u} \cdot \nabla T=-\mathbf{u}^{\prime} \cdot \nabla \bar{T}-\overline{\mathbf{u}} \cdot \nabla T^{\prime}-\mathbf{u}^{\prime} \cdot \nabla T^{\prime}-\overline{\mathbf{u}} \cdot \nabla \bar{T}$,

where overbars denote a smoothed daily climatology, primes denote deviation therefrom, $\nabla \equiv(\partial / \partial x, \partial / \partial y, 0)$ and $\mathbf{u}=(u, v, 0)$. Removing the smoothed seasonal cycle from the advection terms yields the following expression for the advection anomaly:

$$
\begin{aligned}
-\mathbf{u} \cdot \nabla T+\overline{\mathbf{u} \cdot \nabla T}= & \left(-\mathbf{u}^{\prime} \cdot \nabla \bar{T}+\overline{\mathbf{u}^{\prime} \cdot \nabla \bar{T}}\right)+\left(-\overline{\mathbf{u}} \cdot \nabla T^{\prime}\right. \\
& \left.+\overline{\overline{\mathbf{u}} \cdot \nabla T^{\prime}}\right)+\left(-\mathbf{u}^{\prime} \cdot \nabla T^{\prime}+\overline{\mathbf{u}^{\prime} \cdot \nabla T^{\prime}}\right) \\
& +(-\overline{\mathbf{u}} \cdot \nabla \bar{T}+\overline{\overline{\mathbf{u}} \cdot \nabla \bar{T}})
\end{aligned}
$$

and because the overbars denote a smoothed daily climatology, rather than a standard time mean, Reynold's postulates (e.g., Holton and Hakim 2013, p. 257) do not hold exactly. The mean of any primed quantity, albeit nearly equal to zero, is not exactly equal to zero and, for example, $\overline{\mathbf{u}} \cdot \nabla \bar{T} \neq \overline{\overline{\mathbf{u}} \cdot \nabla \bar{T}}$.

Equation (3) states that the horizontal temperature advection anomaly is driven by the anomalous advection of the climatological temperature field by the anomalous wind $-\mathbf{u}^{\prime} \cdot \nabla \bar{T}+\overline{\mathbf{u}^{\prime} \cdot \nabla \bar{T}}$, the anomalous advection of the anomalous temperature by the climatological wind $-\overline{\mathbf{u}} \cdot \nabla T^{\prime}+\overline{\overline{\mathbf{u}} \cdot \nabla T^{\prime}}$, the anomalous advection of the anomalous temperature by the anomalous wind $-\mathbf{u}^{\prime} \cdot \nabla T^{\prime}+\overline{\mathbf{u}^{\prime} \cdot \nabla T^{\prime}}$, and an additional term reflecting the small difference between $\overline{\mathbf{u}} \cdot \nabla \bar{T}$ and $\overline{\mathbf{u}} \cdot \nabla \bar{T}$. Removing the seasonal cycles from each term in (1) and combining the result with (3) yields

$$
\begin{aligned}
\frac{\partial T^{\prime}}{\partial t}= & \left(-\mathbf{u}^{\prime} \cdot \nabla \bar{T}+\overline{\mathbf{u}^{\prime} \cdot \nabla \bar{T}}\right)+\left(-\overline{\mathbf{u}} \cdot \nabla T^{\prime}+\overline{\overline{\mathbf{u}} \cdot \nabla T^{\prime}}\right) \\
& +\left(-\mathbf{u}^{\prime} \cdot \nabla T^{\prime}+\overline{\mathbf{u}^{\prime} \cdot \nabla T^{\prime}}\right)+(-\overline{\mathbf{u}} \cdot \nabla \bar{T}+\overline{\overline{\mathbf{u}} \cdot \nabla \bar{T}}) \\
& -\left(\dot{\eta} \frac{\partial T}{\partial \eta}\right)^{\prime}+\left(\frac{\kappa T \omega}{p}\right)^{\prime}+P_{T}^{\prime}+\mathrm{Res}^{\prime} .
\end{aligned}
$$

To determine whether presumptions of previous studies are correct, that is, that $-\mathbf{u}^{\prime} \cdot \nabla \bar{T}$ drives the growth of the NAO's SAT anomalies, we follow a methodology similar to Seo et al. (2016) and independently integrate composites of each term in (4) using the forward-Euler method. Integrations are computed
TABLE 1. Domains of the major temperature anomalies.

\begin{tabular}{lc}
\hline \multicolumn{1}{c}{ Region } & \multicolumn{1}{c}{ Domain } \\
\hline Greenland and Baffin Bay & $55^{\circ}-85^{\circ} \mathrm{N}, 20^{\circ}-75^{\circ} \mathrm{W}$ \\
Europe and the Barents and Kara Seas & $45^{\circ}-85^{\circ} \mathrm{N}, 5^{\circ} \mathrm{W}-60^{\circ} \mathrm{E}$ \\
United States & $30^{\circ}-50^{\circ} \mathrm{N}, 75^{\circ}-110^{\circ} \mathrm{W}$ \\
Northern Africa & $5^{\circ}-35^{\circ} \mathrm{N}, 10^{\circ} \mathrm{W}-30^{\circ} \mathrm{E}$ \\
\hline
\end{tabular}

at each grid point and then integrated SAT anomaly values are domain averaged over the boxes that outline the major anomalies shown in Fig. 1. Table 1 displays the precise range of latitudes and longitudes included in these domains. The domains are chosen to outline the major anomalies in Fig. 1 for the positive phase; however, the results are not sensitive to the precise domain sizes or locations. Integrations are initiated at lag day -10 over Greenland and Europe and lag day -5 over the United States and northern Africa. Although the conclusions of our analysis are also not sensitive to the precise lag day chosen from which to initiate the integrations, the size of the residual is sensitive, as will be discussed further in section $3 \mathrm{a}$.

For the diabatic heating terms, we use the 12-h accumulated data initiated at 0000 and 1200 UTC. These diabatic terms provided by ERA-Interim are the total diabatic tendency, shortwave radiative tendency and longwave radiative tendency (Berrisford et al. 2009), and the contribution to the diabatic heating by the sum of latent heat release and vertical mixing is given as a residual; that is,

$$
\frac{Q_{\mathrm{lat}}}{c_{p}}+\frac{Q_{\mathrm{mix}}}{c_{p}}=\frac{Q}{c_{p}}-\frac{Q_{\mathrm{rad}}}{c_{p}},
$$

where $Q_{\text {lat }}, Q_{\text {mix }}$, and $Q_{\text {rad }}$ represent the contributions by latent heat release, vertical mixing and radiation (shortwave + longwave) to the total diabatic heating $Q$ [denoted $P_{T}$ in (4)], and $c_{p}$ denotes the specific heat capacity of air (Fueglistaler et al. 2009).

It should be noted that the diabatic heating terms in ERA-Interim are heavily dependent on the parameterization schemes that are used in the reanalysis model and, as such, these terms are subject to errors in the parameterization schemes. Given that the circulation and temperature fields are reasonably well represented in the reanalysis, it can be argued that the total diabatic heating is likely to be reasonably well represented as well. However, there are problems with the representation of clouds over the Arctic that can lead to large errors in the radiation budget (e.g., Prenni et al. 2007), despite the fact that the radiative transfer scheme used by ECMWF has been verified extensively by observations (Mlawer et al. 1997; 
Iacono et al. 2008). Moreover, the values of total column water vapor provided by different reanalysis products can vary (Schröder et al. 2016), diminishing the confidence that should be placed on, for example, the latent heat release contribution to the diabatic heating.

\section{b. Surface energy budget}

The surface energy budget is used to identify relevant contributors to the skin temperature anomaly pattern, which we will show resembles the SAT anomaly pattern except for anomalies overlying the ocean. Following Gong et al. (2017) and Lee et al. (2017), if we let $G$ $\left[\equiv \int_{0}^{\Delta z} \rho c_{p}(d T / d t) d z\right]$ denote energy storage at the surface, then

$$
G=F_{\mathrm{lw}}^{\downarrow}+F_{\mathrm{lw}}^{\uparrow}+F_{\mathrm{sw}}^{\downarrow}+F_{\mathrm{sw}}^{\uparrow}+F_{\mathrm{sh}}+F_{\mathrm{lh}}+R,
$$

where $F_{\mathrm{lw}}$ and $F_{\mathrm{sw}}$ denote longwave and shortwave radiation, respectively, and the superscripts $\uparrow$ and $\downarrow$ denote the upward and downward directions. The quantities $F_{\mathrm{sh}}$ and $F_{\mathrm{lh}}$, respectively, refer to the surface sensible and latent heat fluxes. Terms in the surface energy budget that are not provided by ERA-Interim, such as skin temperature changes associated with conduction through and melting of sea ice, and mixing in the oceanic boundary layer, are contained in $R$. Following the ERA-Interim sign convention, energy fluxes are defined to be positive if they are directed downward.

Taking the differential of (6), as in Lu and Cai (2009), Lesins et al. (2012), Gong et al. (2017), and Lee et al. (2017),

$$
\Delta G=\Delta F_{\mathrm{lw}}^{\downarrow}+\Delta F_{\mathrm{lw}}^{\uparrow}+\Delta F_{\mathrm{sw}}^{\downarrow}+\Delta F_{\mathrm{sw}}^{\uparrow}+\Delta F_{\mathrm{sh}}+\Delta F_{\mathrm{lh}}+\Delta R,
$$

where the differential operator $\Delta$ denotes an anomaly. If $G$ is taken to represent the energy storage within an infinitesimally thin interface at the surface, then $G=0$ (Gong et al. 2017; Lee et al. 2017), which is consistent with the assumption that the ECMWF reanalysis model takes over land, namely that the specific heat capacity is zero (ECMWF 2009). However, the reanalysis model does not assume a zero heat capacity over the ocean and we therefore deviate from the aforementioned studies slightly, by subtracting $\Delta G$ from both sides of (7) yielding

$$
\begin{aligned}
0= & \Delta F_{\mathrm{lw}}^{\downarrow}+\Delta F_{\mathrm{lw}}^{\uparrow}+\Delta F_{\mathrm{sw}}^{\downarrow}+\Delta F_{\mathrm{sw}}^{\uparrow}+\Delta F_{\mathrm{sh}}+\Delta F_{\mathrm{lh}} \\
& +\Delta R-\Delta G,
\end{aligned}
$$

where a new residual is calculated as $\Delta R-\Delta G$ :

$$
\begin{aligned}
\Delta R-\Delta G= & -\Delta F_{\mathrm{lw}}^{\downarrow}-\Delta F_{\mathrm{lw}}^{\uparrow}-\Delta F_{\mathrm{sw}}^{\downarrow}-\Delta F_{\mathrm{sw}}^{\uparrow} \\
& -\Delta F_{\mathrm{sh}}-\Delta F_{\mathrm{lh}} .
\end{aligned}
$$

Because the reanalysis model assumes a zero specific heat capacity over land, the residual over land therefore reflects only physical processes contained in $\Delta R$.

Using the Stefan-Boltzmann law to express $F_{\text {lw }}^{\uparrow}$ as $-\varepsilon_{s} \sigma T_{s}^{4}$, where $\varepsilon_{s}$ is the surface emissivity, $\sigma$ is the Stefan-Boltzmann constant and $T_{S}$ denotes the skin temperature, (9) can be rewritten as

$$
\Delta T_{s}=\frac{\Delta F_{\mathrm{lw}}^{\downarrow}+\Delta F_{\mathrm{sw}}^{\downarrow}+\Delta F_{\mathrm{sw}}^{\uparrow}+\Delta F_{\mathrm{sh}}+\Delta F_{\mathrm{lh}}+\Delta R-\Delta G}{4 \varepsilon_{s} \sigma\left\{T_{s}\right\}^{3}},
$$

which implies that the skin temperature anomaly may change in response to changes in anomalies of downward longwave radiation, net shortwave radiation, surface heat fluxes and residual processes. For the purpose of this study, $\varepsilon_{s}$ is approximated to be 1.0 and $\left\{T_{s}\right\}$ is the DJF-mean skin temperature.

To examine this surface energy budget, 12-h accumulated data initiated at 0000 and 1200 UTC are averaged together after dividing by the 12-h time step (in seconds), and the skin temperature anomaly is set to its daily mean value (average of 0000, 0600, 1200, and 1800 UTC). Composite anomaly fields of each term in (10) are then produced.

\section{Results}

\section{a. The thermodynamic energy equation on the lowest eta surface}

Domain area-weighted averages (see Table 1) of the composite temperature on the lowest eta surface indicate that between lag day -10 and lag day +1 , the temperature changes by nearly $2 \mathrm{~K}$ over Europe and Greenland, during both phases of the NAO (Figs. 3 and 4). The dominant contributor to these temperature changes is indeed horizontal temperature advection, which is composed of four components [(3)]. Figures 3 and 4 indicate that the advection of climatological temperature by the anomalous wind is the dominant contributor to the horizontal temperature advection, whereas the other advection terms $\left(-\overline{\mathbf{u}} \cdot \nabla T^{\prime}+\overline{\overline{\mathbf{u}}} \cdot \nabla T^{\prime}\right.$ and $\left.-\mathbf{u}^{\prime} \cdot \nabla T^{\prime}+\overline{\mathbf{u}^{\prime} \cdot \nabla T^{\prime}}\right)$ are smaller, or are of opposite sign (this point is discussed with more detail in Clark and Feldstein (2019, hereafter Part II)]. The term $(-\overline{\mathbf{u}} \cdot \nabla \bar{T}+\overline{\mathbf{u}} \cdot \nabla \bar{T})$ is more than two orders of magnitude smaller than the temperature change and is therefore omitted from Figs. 3 and 4, as is the shortwave radiative tendency. 


\section{Composite Against the Positive NAO}
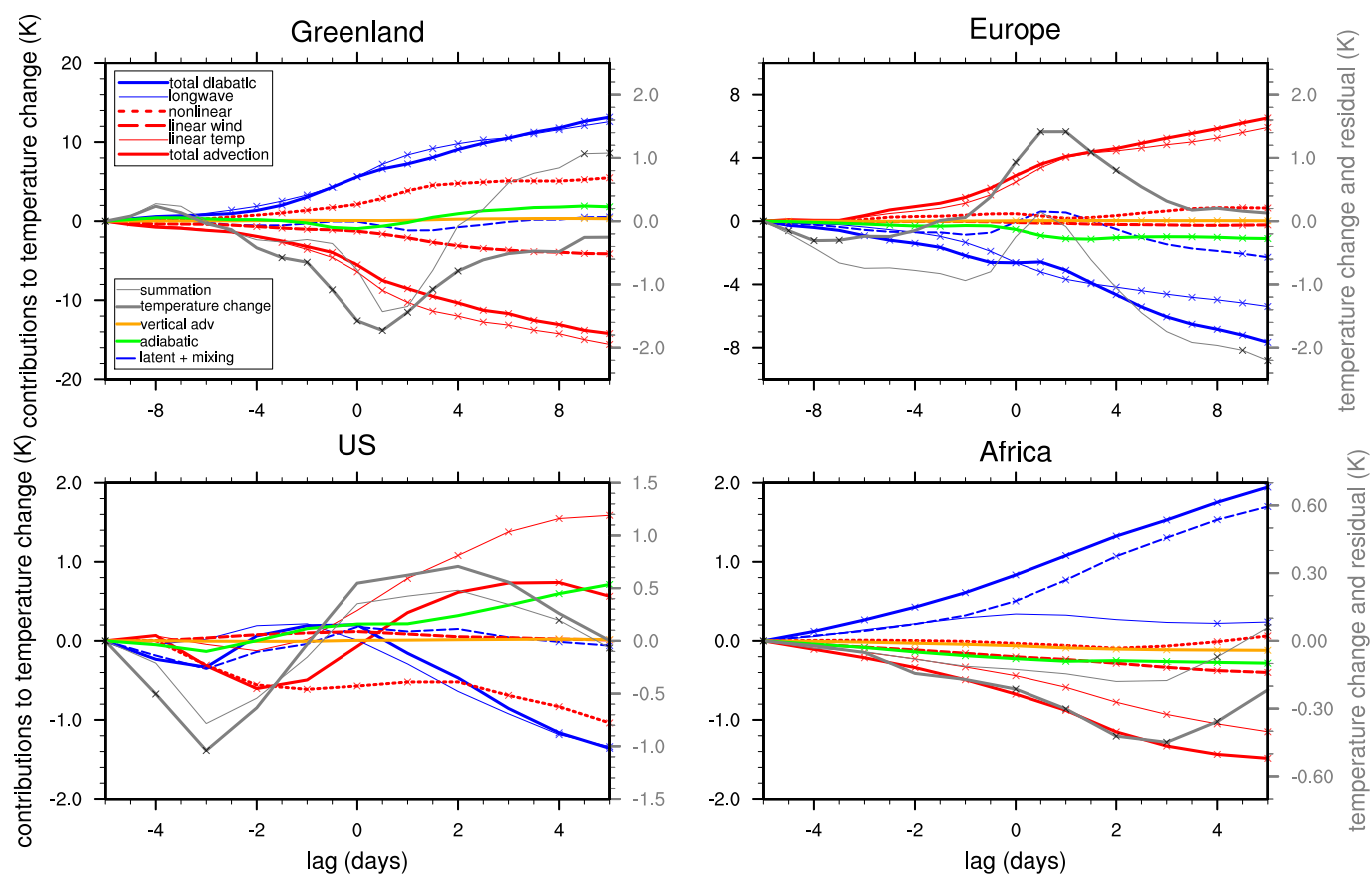

FIG. 3. The composite thermodynamic heat budget on the lowest eta surface, domain averaged over the regions indicated by the titles of each panel (see Table 1). The thick and thin gray lines respectively show the temperature change and summation [(15)] and correspond to the right axis. The remaining terms correspond to the left axis. The thick, thin, dashed, and dotted red lines respectively show the contribution to temperature change by $-u \cdot \nabla T+\overline{u \cdot \nabla T},-u^{\prime} \cdot \nabla \bar{T}+\overline{u^{\prime} \cdot \nabla \bar{T}},-\bar{u} \cdot \nabla T^{\prime}+\overline{\bar{u} \cdot \nabla T^{\prime}}$, and $-u^{\prime} \cdot \nabla T^{\prime}+\overline{u^{\prime} \cdot \nabla T^{\prime}}$. The thick, thin, and dashed blue lines respectively show the contribution to temperature change by the total diabatic heating, longwave radiative heating, and latent heating + vertical mixing. The orange line shows the contribution to temperature change by vertical advection and the green line shows the contribution to temperature change by adiabatic warming. Statistical significance at $p<0.10$ is indicated with $\times$ marks.

On its own, the advection of the climatological temperature by the anomalous wind changes the temperature by far more than what is observed between lag day -10 and lag day +10 . In this time interval, the contribution to temperature change by the advection of the climatological temperature by the anomalous wind is nearly $8 \mathrm{~K}$ over Europe during both NAO phases, which is about 4 times larger than the maximum observed temperature change observed at lag day +1 . Similarly, over Greenland, the advection of the climatological temperature by the anomalous wind changes the temperature by more than $15 \mathrm{~K}$, which is about 8 times greater than the maximum observed temperature change observed at lag day +1 .

The very large temperature changes associated with the advection of the climatological temperature by the anomalous wind implies that there must be one or more processes in opposition to this advection term. Figures 3 and 4 show that this is accomplished by diabatic heating. Specifically, over Greenland, Europe and the United States, longwave heating/cooling dominates the diabatic heating contribution to temperature change and at most lags there is a near balance between the longwave heating/cooling and horizontal temperature advection, with the former being larger in magnitude than the latter at positive lags, and vice versa at negative lags. This relationship is of course to be expected if these two processes are to account for the growth and decay of the temperature anomalies. Furthermore, for all three regions and both NAO phases, it is seen that warm advection is opposed by longwave cooling and cold advection by longwave warming. This relationship can be conceptualized by considering the Newtonian cooling approximation to the radiative transfer equation (Fueglistaler et al. 2009):

$$
\frac{Q_{\mathrm{lw}}}{c_{p}} \approx-\tau^{-1} T^{\prime},
$$

where $\tau$ is the relaxation time scale. Figures 3 and 4 imply that the advection of climatological temperature by the 


\section{Composite Against the Negative NAO}
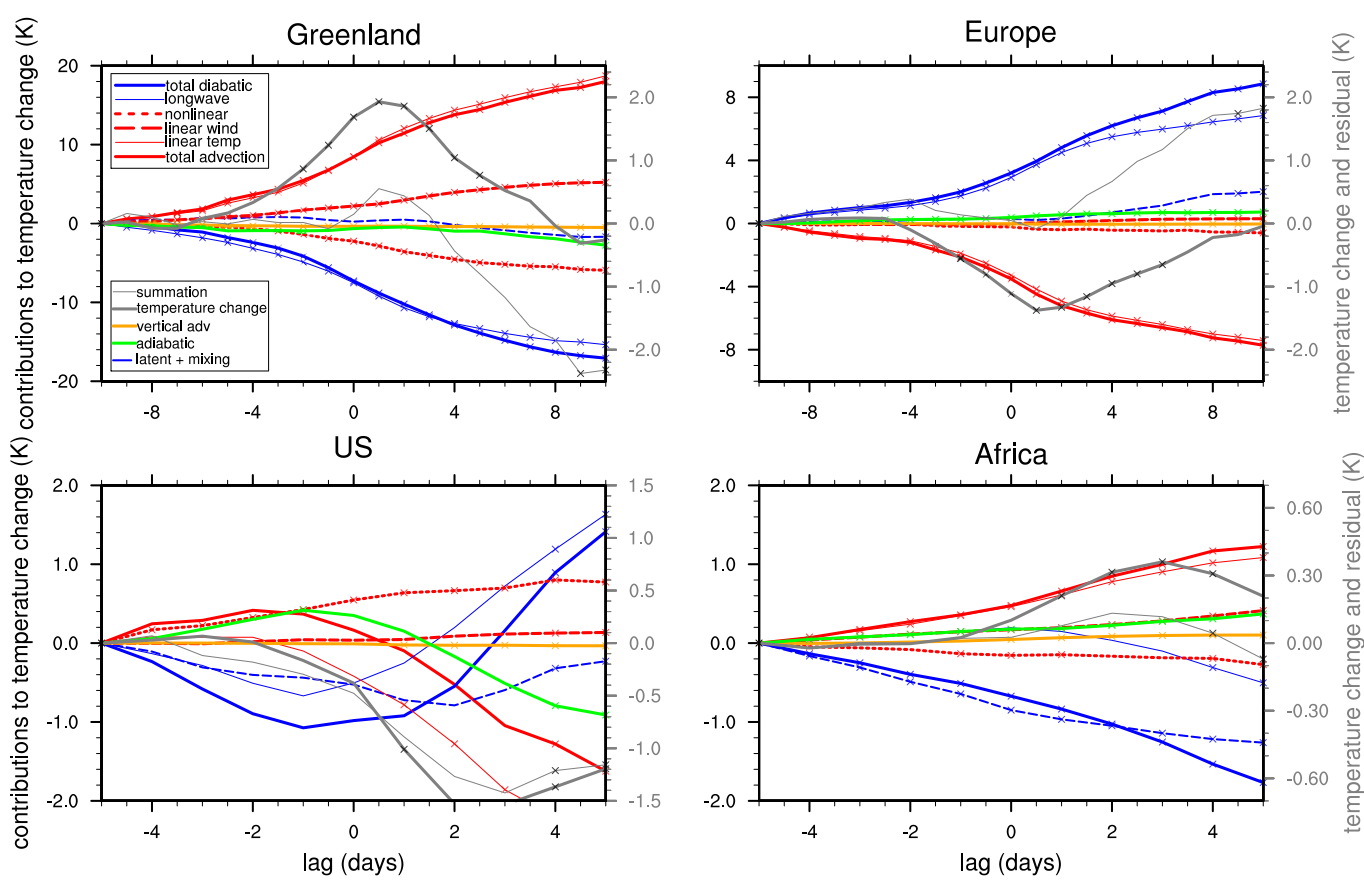

FIG. 4. As in Fig. 3, but for the negative phase of the NAO.

anomalous wind produces a temperature perturbation $T^{\prime}$, which causes the longwave heating/cooling to respond in accordance with (11).

Over Greenland, Europe and the United States, the longwave cooling (heating) eventually comes into balance with warm (cold) horizontal temperature advection, with the longwave cooling (heating) ultimately causing the temperature to return to its climatological value. Unlike Greenland, Europe and the United States, the diabatic heating process in opposition to horizontal temperature advection over northern Africa is the sum of latent heat release and vertical mixing. We presume that vertical mixing is much stronger than latent heat release near the surface over northern Africa and conceptualize this relationship using an approximation to the vertical divergence of the eddy potential temperature flux from flux-gradient theory (e.g., Holton and Hakim 2013, p. 264):

$$
\frac{\partial\left[\theta^{*} w^{*}\right]}{\partial z}=-K_{h} \frac{\partial^{2}[\theta]}{\partial z^{2}} \propto[\theta],
$$

where the square brackets denote a time mean long enough to average out the small-scale eddy fluctuations and short enough to retain the large-scale flow (Holton and Hakim 2013, p. 256), asterisks denote deviation therefrom, $w$ is the vertical velocity, and $K_{h}$ is the eddy diffusivity of heat. Equation (12) implies that a vertical divergence of eddy potential temperature flux (cooling) occurs in response to an increase in potential temperature by warm advection, and vice versa. Evidently, this process is more important near the surface over northern Africa than it is over Greenland, Europe and the United States. Thus, in the same way that longwave heating causes the SAT to return to its climatological value over Greenland, Europe and the United States, vertical mixing eventually causes the SAT to return to its climatological value over northern Africa.

Figures 3 and 4 also feature a large residual (implied by the difference between the summation curve and the temperature change curve), particularly over Europe and northern Africa. This is inevitable because it is not possible, with the data that ECMWF provide, to diagnostically calculate the contributions to temperature change by all variables on the right-hand side (RHS) of (1) in precisely the same way that the reanalysis model calculates the contributions to temperature change. However, if it were possible to diagnostically calculate the contributions to temperature change by all variables on the RHS of (1) in the same way that the reanalysis model does, then there would be no residual in Figs. 3 and 4. That being said, the growth of the residual over time suggests that numerical truncation is perhaps the ultimate cause.

Consider the residual, defined as 


$$
\text { Res } \equiv \frac{\partial T}{\partial t}+u \frac{\partial T}{\partial x}+v \frac{\partial T}{\partial y}+\dot{\eta} \frac{\partial T}{\partial \eta}-\frac{\kappa T \omega}{p}-P_{T} .
$$

This quantity may be small at a particular instant but may have the same sign for several consecutive days such that when integrated over time, it becomes large. It is possible, for example, that our estimate of vertical temperature advection (which is difficult to diagnostically calculate in eta coordinates-see the appendix) has a systematic bias that can account for the growth of the residual over time.

The residual, corresponding to the difference between the summation and temperature curves in Figs. 3 and 4 , is

$$
\begin{aligned}
\int_{t}^{t+\Delta t} \operatorname{Res}^{\prime} d t= & T^{\prime}(t+\Delta t)-T^{\prime}(t)+\int_{t}^{t+\Delta t}\left(u \frac{\partial T}{\partial x}+v \frac{\partial T}{\partial y}\right. \\
& \left.+\dot{\eta} \frac{\partial T}{\partial \eta}-\frac{\kappa T \omega}{p}-P_{T}\right)^{\prime} d t
\end{aligned}
$$

The fact that the temperature change has a much smaller amplitude (up to 20 times smaller at some lag days) than the dominant terms (e.g., temperature advection and longwave heating/cooling) implies that the residual, given by (14), will be rather sensitive to small errors in the calculation of these dominant terms. For example, over Greenland during the negative phase of the NAO (Fig. 4), the residual (inferred by the difference between the summation and temperature change curves) is about $-1.5 \mathrm{~K}$ at lag day +1 , which is rather small compared to the temperature advection $(\sim 10 \mathrm{~K})$ and longwave cooling $(\sim-9.5 \mathrm{~K})$ contributions at the same time lag. Because the residual is expected to be sensitive to small errors in the dominant terms and because the summation term, which is given by

$$
\mathrm{Sum}=\int_{t}^{t+\Delta t}\left(u \frac{\partial T}{\partial x}+v \frac{\partial T}{\partial y}+\dot{\eta} \frac{\partial T}{\partial \eta}-\frac{\kappa T \omega}{p}-P_{T}\right)^{\prime} d t
$$

fluctuates with the temperature change $T^{\prime}(t+\Delta t)-T^{\prime}(t)$ (cf. the thin and thick black lines in Figs. 3 and 4), we believe that this thermodynamic budget analysis is useful, in spite of the large residual term.

\section{b. The surface energy budget}

Using (10), we examine the dominant drivers of the skin temperature anomaly field (the leftmost column in Figs. 5 and 6; shown as pentad averages). As with the SAT anomaly pattern, the skin temperature anomaly pattern is characterized by warming over the eastern United States, Europe, and the Barents and Kara Seas and cooling over northern Africa, Greenland, and Baffin Bay during the positive phase of the NAO. During the negative phase of the NAO, the reverse skin temperature anomaly pattern is observed. However, unlike the SAT anomaly pattern, the skin temperature anomaly pattern is weaker over open water (see http://nsidc.org, which shows the 1981-2010 climatological median sea ice edge) south of Greenland and north of Scandinavia and Russia (see Fig. 7).

Of all the terms in the surface energy budget, the downward longwave radiation anomaly pattern most closely resembles the skin temperature anomaly pattern (as indicated by the pattern correlation depicted in the top-left corner of each panel), consistent with Luo et al. (2017, 2019), which implies that it prominently contributes to the changes in skin temperature during both phases of the NAO. This is in contrast with the SAT anomaly pattern, which is driven by horizontal temperature advection (Figs. 3 and 4). Together, Figs. 3-6 suggest that horizontal temperature advection drives the NAO's SAT anomaly pattern, while the associated changes in downward longwave radiation, which may arise through the anomalies in air temperature, water vapor, or cloudiness, drive the NAO's skin temperature anomaly pattern.

Although it is clear that downward longwave radiation is an important contributor to the skin temperature anomaly pattern of the NAO (Figs. 5 and 6 ), the cause for the downward longwave radiation anomaly pattern remains unclear. It is possible, if not likely, for example, that temperature, water vapor and cloud fraction anomalies are not equally important for the downward longwave radiation anomaly pattern of the NAO. In Part II of this study, we quantify the contributions to the downward longwave radiation anomaly pattern of the NAO by anomalies in air temperature, water vapor and clouds using both reanalysis data and the Rapid Radiative Transfer Model (RRTMG; Mlawer et al. 1997; Iacono et al. 2008).

Over the ocean north of Russia, south of Greenland and off the coast of the eastern United States, Figs. 5 and 6 indicate the presence of large-amplitude surface sensible and latent heat fluxes, also consistent with Luo et al. $(2017,2019)$. These heat fluxes tend to be of smaller amplitude over the land, where the air is more stably stratified, particularly over Greenland, compared to the air that overlies the ocean. The sensible and latent heat fluxes are largely balanced by the residual term $\Delta R-\Delta G$ (rightmost columns in Figs. 5 and 6), which may be due to mixing within the oceanic boundary layer, or other residual processes contained in $\Delta R$. The spatial pattern of the sensible and latent heat fluxes likely reflects the fact that a strong vertical temperature 


\section{Composites against the Positive NAO}
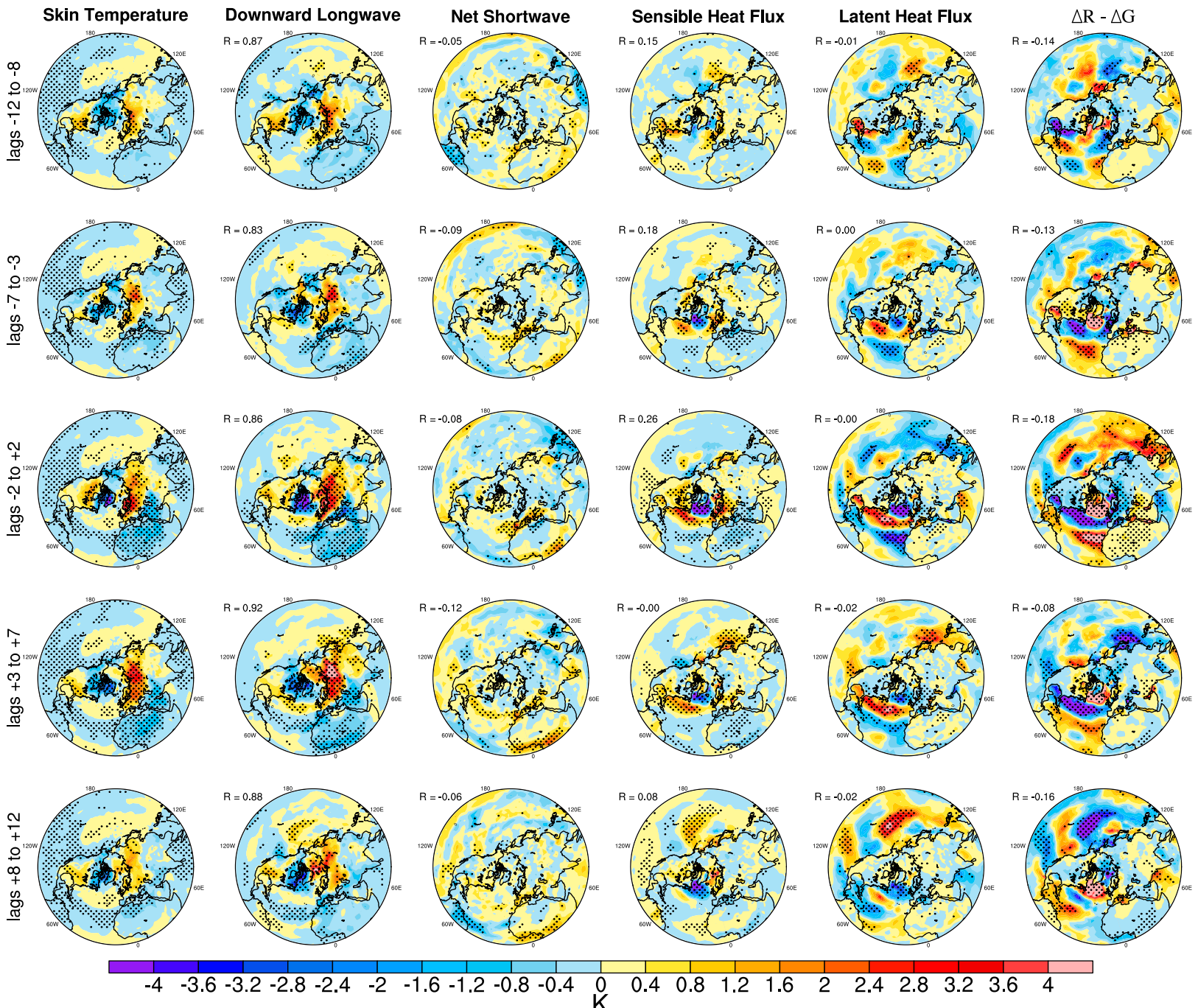

FIG. 5. Surface energy budget composite during the positive phase of the NAO. (from left to right) Columns display composite anomalies of skin temperature, downward longwave radiation, net shortwave radiation, sensible heat flux, latent heat flux, and the residual term (see text). Rows display time lags (as pentad averages). All fluxes are normalized by the quantity $4 \varepsilon_{s} \sigma\left\{T_{s}\right\}^{3}$, which ensures that their units are kelvins (see text). Pattern correlations with the skin temperature (weighted by the square root of the cosine of latitude) within the domain $20^{\circ}-80^{\circ} \mathrm{N}, 90^{\circ} \mathrm{W}-40^{\circ} \mathrm{E}$ are shown in the top-left corner of each panel.

contrast develops between the air and underlying ocean surface over these regions (see Fig. 7) and that enhanced zonal winds develop over the central North Atlantic Ocean in response to an increase in the meridional pressure gradient for the positive $\mathrm{NAO}$, and vice versa for the negative NAO. The vertical temperature contrast that arises from the large thermal inertia of the ocean is clearly reflected by the magnitude of the residual term $\Delta R-\Delta G$ over the ocean, shown in Figs. 5 and 6.

As stated above, once the advection of the climatological temperature by the anomalous wind changes the
SAT, an enhanced vertical temperature gradient develops near the surface over the Atlantic Ocean (Fig. 7) because the sea surface temperature remains approximately constant relative to the overlying air. A large vertical temperature gradient does not develop near the surface of the continents surrounding the Atlantic Ocean because the landmasses have a smaller specific heat capacity than the ocean (in fact, the reanalysis model assumes a specific heat capacity of zero over the land; ECMWF 2009). As a result, the anomalous surface heat fluxes shown in Figs. 5 and 6 develop over the ocean, but not over the land. These findings suggest 


\section{Composites against the Negative NAO}
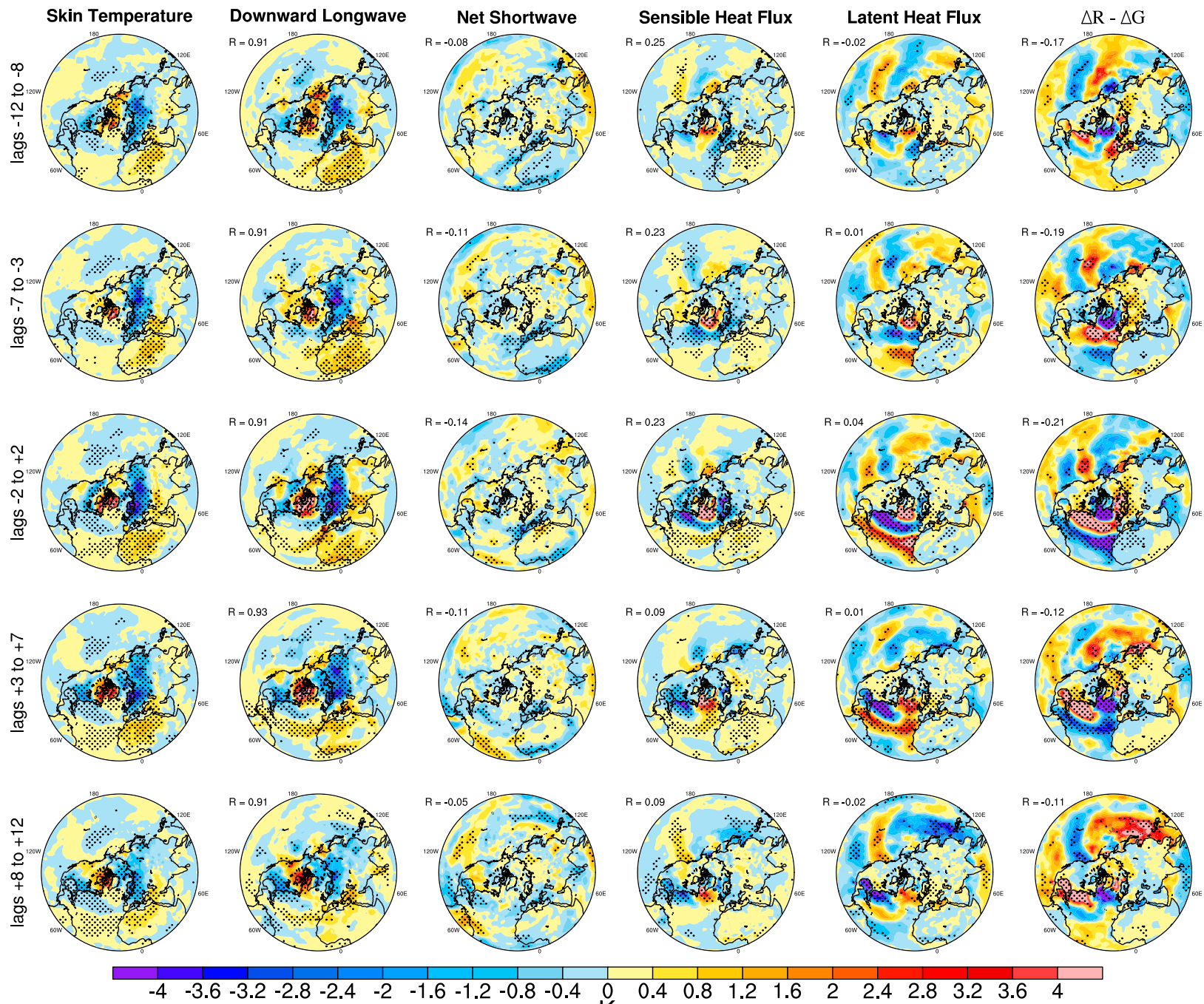

$\begin{array}{lllllllllllll}-4 & -3.6 & -3.2 & -2.8 & -2.4 & -2 & -1.6 & -1.2 & -0.8 & -0.4 & 0 \\ \mathrm{~K}\end{array}$

\section{0}

$\begin{array}{llllllllll}0.4 & 0.8 & 1.2 & 1.6 & 2 & 2.4 & 2.8 & 3.2 & 3.6 & 4\end{array}$

FIG. 6. As in Fig. 5, but for the negative phase of the NAO.

that the anomalous surface heat fluxes develop in response to horizontal temperature advection, especially over the ocean, where the SAT changes over a surface whose temperature remains relatively constant due to its large specific heat capacity.

Upon close examination of Figs. 5 and 6, the amplitude of the latent heat flux anomalies of the negative NAO phase appear larger than those of the positive phase. However, a Student's $t$ test indicates that the difference in amplitude between the two phases is not statistically significant. The latent heat flux anomaly pattern of both NAO phases largely matches the sensible heat flux anomaly patterns, but with a particularly large amplitude in the regions where the meridional pressure gradient is enhanced, consistent with accelerated zonal wind anomalies and presumably enhanced evaporation from the ocean's surface.

Comparing the third columns to the leftmost columns in Figs. 5 and 6, it is seen that the net shortwave radiation anomaly is relatively weak in amplitude and does not contribute to the skin temperature anomaly pattern (perhaps not surprisingly given that net shortwave radiation tends to be unimportant in the wintertime). The pattern correlation between the net shortwave radiation anomaly pattern and the skin temperature anomaly pattern remains substantially smaller than the pattern correlation between the skin temperature anomaly pattern and the other terms. In spite of this, there are statistically significant signals of net shortwave radiation over the North Atlantic equatorward of $30^{\circ} \mathrm{N}$ and at lag 


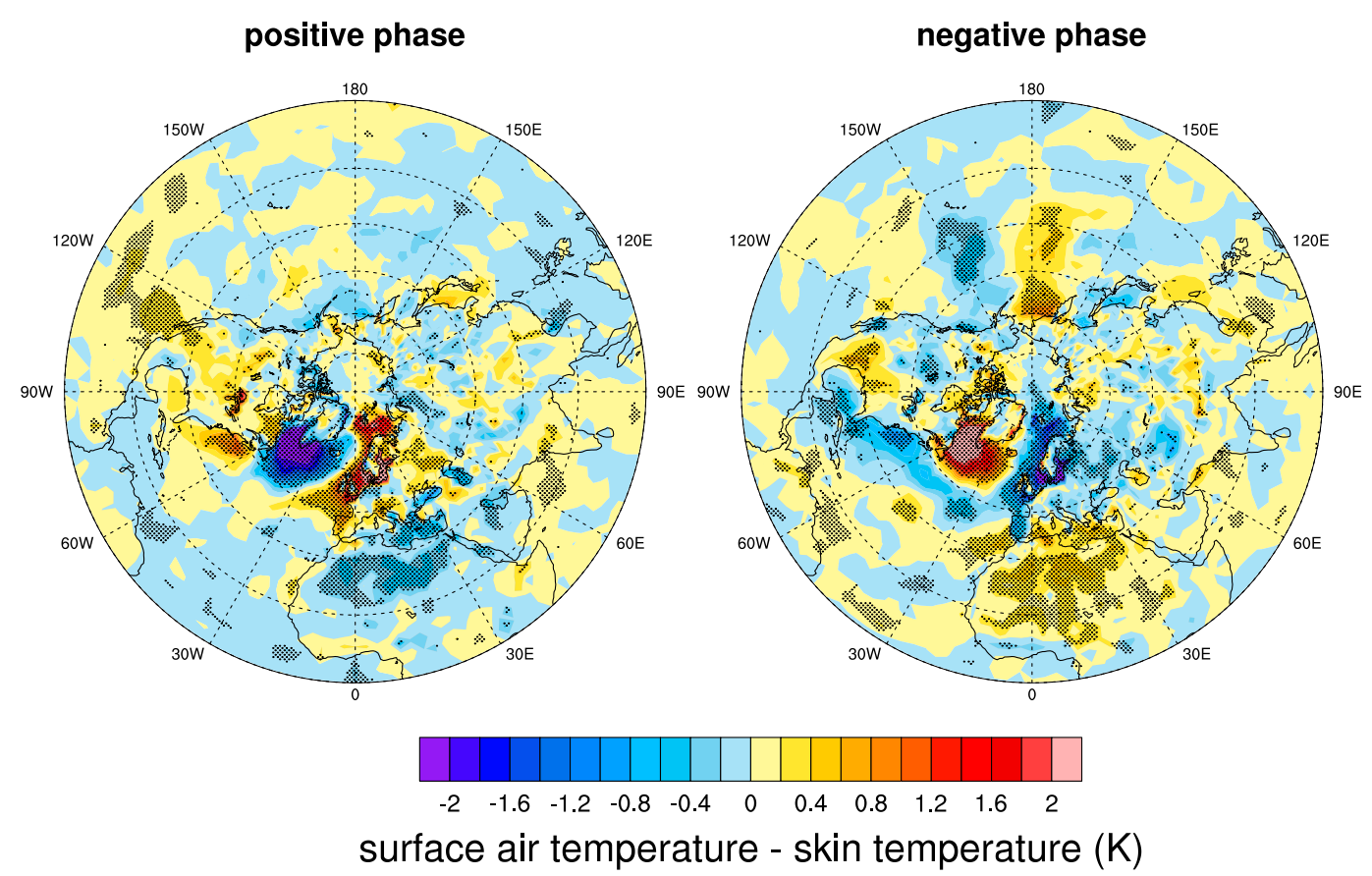

FIG. 7. The composite difference between the surface air temperature anomaly and skin temperature anomaly at lag day 0 during the (left) positive and (right) negative phases of the NAO.

day +10 that appear in the opposite sense between the positive and negative NAO phases (Figs. 5 and 6). Repeated resamplings of the data show that the pattern correlation between the net shortwave anomaly patterns of the two NAO phases $(r \sim-0.6)$ is statistically significant at $p<0.0001$.

\section{Summary and conclusions}

This study separately evaluates the growth and decay of the SAT and skin temperature anomaly patterns associated with the NAO. A composite-based approach is taken, showing that the SAT and skin temperature anomaly patterns of the NAO are similar and composed of four different anomalies that develop over Greenland/Baffin Bay, Europe/Barents and Kara Seas, the United States, and northern Africa. Diagnostic evaluation of the thermodynamic energy equation on the lowest model level surface provided by ERAInterim shows that the driver of the SAT anomaly pattern is different from that of the skin temperature anomaly pattern, despite the large spatial correspondence between them. This suggests that the surface energy budget, although a useful diagnostic tool for understanding changes in skin temperature, should not be applied to understand changes in SAT (e.g., Gong et al. 2017; Lee et al. 2017). The SAT anomaly pattern develops through horizontal temperature advection, specifically through advection of the climatological temperature field by the anomalous wind, while the skin temperature anomaly pattern develops through changes in downward longwave radiation. In Part II, we address the question of whether air temperature, water vapor, or cloud fraction anomalies cause the downward longwave radiation anomalies of the NAO. Apart from highlighting the different drivers of skin temperature and SAT, the evaluation of the thermodynamic equation on the lowest model level shows that the decay of the SAT anomalies is through longwave radiative heating/cooling over Greenland, Europe, and the United States, and through vertical mixing over northern Africa.

There is evidence that the large-amplitude surface heat fluxes present over the ocean during the NAO ultimately arise in response to a vertical temperature gradient that develops there, as a result of the large thermal inertia of the ocean. It is shown that horizontal temperature advection causes the SAT to change, while the ocean's surface temperature remains nearly constant. The surface energy budget indicates that while these large-amplitude surface heat fluxes overlie the ocean, the downward longwave radiation anomaly pattern most strongly resembles the skin temperature anomaly pattern. This leads to the conclusion that, while heat fluxes contribute to skin temperature anomalies over the ocean, downward longwave radiation is the dominant driver of the skin temperature anomaly pattern. 


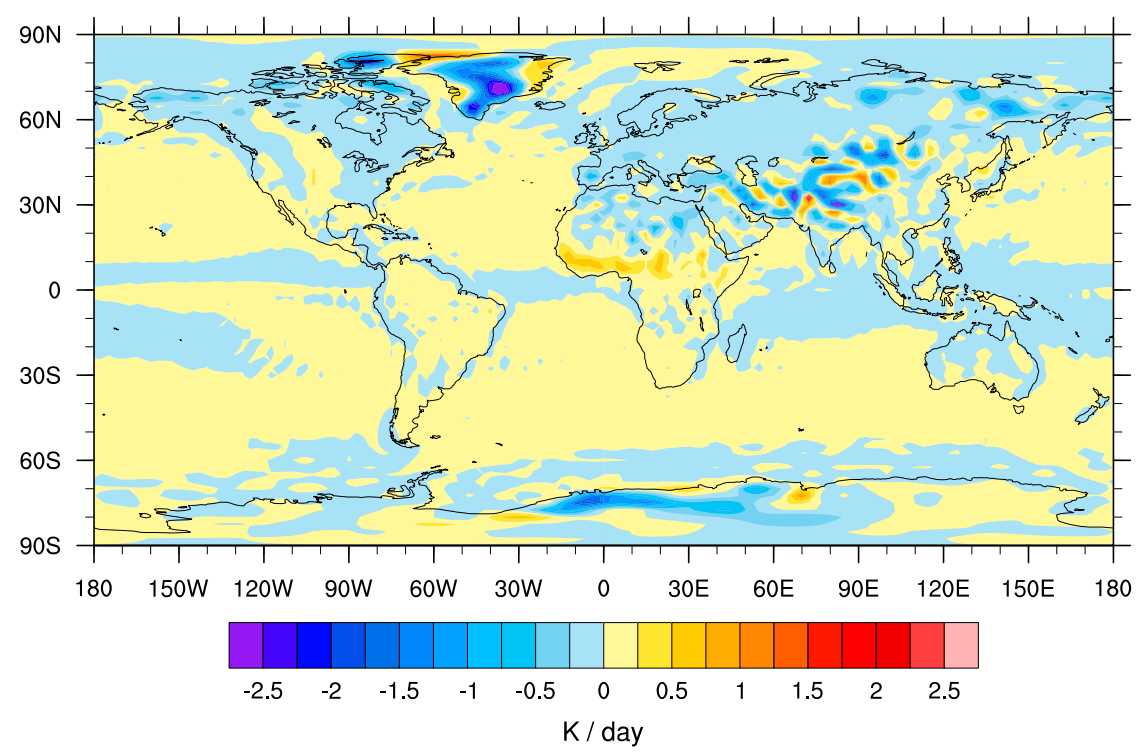

FIG. A1. Climatology of vertical temperature advection on the lowest model level $(\dot{\eta} \partial T / \partial \eta)_{60}$ estimated using the methods outlined in the appendix.

Acknowledgments. We thank the ECMWF team, especially Paul Berrisford and Michail Diamantakis, for providing helpful resources and advice, especially regarding the thermodynamic energy budget on the lowest model level. In addition, we thank two anonymous reviewers for their helpful comments. This study was supported by National Science Foundation Grants OPP-1723832 and AGS-1822015.

\section{APPENDIX}

\section{Calculation of the Vertical Advection Term}

We estimate the vertical advection of temperature on the lowest model level using an approach that mirrors that in the reanalysis model. The vertical advection of any particular quantity $X$ is discretized [ECMWF 2014, their (2.19)] in the reanalysis model as

$$
\begin{aligned}
\left(\dot{\eta} \frac{\partial X}{\partial \eta}\right)_{k}= & \frac{1}{2 \Delta p_{k}}\left[\left(\dot{\eta} \frac{\partial p}{\partial \eta}\right)_{k+1 / 2}\left(X_{k+1}-X_{k}\right)\right. \\
& \left.+\left(\dot{\eta} \frac{\partial p}{\partial \eta}\right)_{k-1 / 2}\left(X_{k}-X_{k-1}\right)\right],
\end{aligned}
$$

which is a scheme introduced originally by Simmons and Burridge (1981), where $p$ is pressure, $k$ denotes an integer model level number, $\eta$ is the vertical coordinate, and $\dot{\eta}$ is the Lagrangian tendency of $\eta$. The variable $\Delta p_{k}$ is given by

$$
\begin{aligned}
\Delta p_{k}=p_{k+1 / 2}-p_{k-1 / 2}= & \left(A_{k+1 / 2}-A_{k-1 / 2}\right) \\
& +\left(B_{k+1 / 2}-B_{k-1 / 2}\right) p_{s},
\end{aligned}
$$

where $p_{k+1 / 2}$ is the pressure on the $k+1 / 2$ "half level," $p_{s}$ is the surface pressure, and $A_{k+1 / 2}$ and $B_{k+1 / 2}$ are constants dependent only $k$ (see Berrisford et al. 2009, their Table 2). The vertical temperature advection on the lowest model level, $k=60$ is then given by

$$
\left(\dot{\eta} \frac{\partial T}{\partial \eta}\right)_{60}=\frac{1}{2 \Delta p_{60}}\left[\left(\dot{\eta} \frac{\partial p}{\partial \eta}\right)_{59+1 / 2}\left(T_{60}-T_{59}\right)\right],
$$

because $(\dot{\eta} \partial p / \partial \eta)_{60+1 / 2}\left(X_{61}-X_{60}\right)=0$ where the boundary condition $\dot{\eta}=0$ applies (ECMWF 2014). Here, $T_{60}$ and $T_{59}$ are provided by ERA-Interim and we estimate $(\dot{\eta} \partial p / \partial \eta)_{59+1 / 2}$ by combining (2.14) and (2.18) in ECMWF (2014):

$$
\begin{aligned}
\left(\dot{\eta} \frac{\partial p}{\partial \eta}\right)_{59+1 / 2}= & -p_{s}\left[B_{59+1 / 2} \frac{\partial}{\partial t}\left(\ln p_{s}\right)-\frac{\partial}{\partial t}\left(\ln p_{s}\right)\right. \\
& \left.+\frac{1}{p_{s}} D_{60} \Delta p_{60}+\left(\mathbf{u}_{60} \cdot \nabla \ln p_{s}\right) \Delta B_{60}\right],
\end{aligned}
$$

where $\Delta B_{60}=B_{60+1 / 2}-B_{59-1 / 2}$. The surface pressure, surface pressure tendency, horizontal divergence, and horizontal wind may be downloaded explicitly from ERA-Interim. A DJF climatology of the vertical temperature advection using this estimate is shown in Fig. A1. The figure shows reasonable magnitudes around regions of high topography such as over Greenland and 
the Himalayas, where vertical motions are expected to be strong.

\section{REFERENCES}

Barnston, A. G., and R. E. Livezey, 1987: Classification, seasonality and persistence of low-frequency atmospheric circulation patterns. Mon. Wea. Rev., 115, 1083-1126, https://doi.org/ 10.1175/1520-0493(1987)115<1083:CSAPOL > 2.0.CO;2.

Benedict, J. J., S. Lee, and S. B. Feldstein, 2004: Synoptic view of the North Atlantic Oscillation. J. Atmos. Sci., 61, 121-144, https:// doi.org/10.1175/1520-0469(2004)061<0121:SVOTNA > 2.0.CO;2.

Berrisford, P., D. Dee, K. Fielding, M. Fuentes, P. Kallberg, S. Kobayashi, and S. Uppala, 2009: The ERA Interim archive: Version 1.0. ECMWF ERA Rep., 16 pp., http://ecmwf.int/ publications/library/do/references/show?id $=89203$.

Clark, J. P., and S. B. Feldstein, 2019: What drives the North Atlantic Oscillation's temperature anomaly pattern? Part II: A decomposition of the surface downward longwave radiation anomalies. J. Atmos. Sci., 77, 199-216, https://doi.org/ 10.1175/JAS-D-19-0028.1.

Chen, Y., J. A. Francis, and J. R. Miller, 2002: Surface temperature of the Arctic: Comparison of TOVS satellite retrievals with surface observations. J. Climate, 15, 3698-3708, https://doi.org/ 10.1175/1520-0442(2002)015<3698:STOTAC $>2.0 . C O ; 2$.

Dee, D. P., and Coauthors, 2011: The ERA-Interim reanalysis: Configuration and performance of the data assimilation system. Quart. J. Roy. Meteor. Soc., 137, 553-597, https://doi.org/ 10.1002/qj.828.

Diao, Y., S. P. Xie, and D. Luo, 2015: Asymmetry of winter European surface air temperature extremes and the North Atlantic Oscillation. J. Climate, 28, 517-530, https://doi.org/ 10.1175/JCLI-D-13-00642.1.

ECMWF, 2009: Part IV: Physical processes. IFS documentationCy40r1, ECMWF Rep., 162 pp.

__, 2014: Part III: Dynamics and numerical procedures. Documentation-Cy40r1, ECMWF Rep., 29 pp.

Feldstein, S. B., 2000: The timescale, power spectra, and climate noise properties of teleconnection patterns. J. Climate, $\mathbf{1 3}$, 4430-4440, https://doi.org/10.1175/1520-0442(2000)013<4430: TTPSAC $>2.0 . \mathrm{CO} ; 2$.

Franzke, C., S. Lee, and S. B. Feldstein, 2004: Is the North Atlantic Oscillation a breaking wave? J. Atmos. Sci., 61, 145-160, https://doi.org/10.1175/1520-0469(2004)061<0145: ITNAOA $>2.0 . \mathrm{CO} ; 2$.

Fueglistaler, S., B. Legras, A. Beljaars, J. J. Morcrette, A. Simmons, A. M. Tompkins, and S. Uppala, 2009: The diabatic heat budget of the upper troposphere and lower/mid stratosphere in ECMWF reanalyses. Quart. J. Roy. Meteor. Soc., 135, 21-37, https://doi.org/10.1002/qj.361.

Gong, T., S. B. Feldstein, and S. Lee, 2017: The role of downward infrared radiation in the recent Arctic winter warming trend. $\mathrm{J}$. Climate, 30, 4937-4949, https://doi.org/10.1175/JCLI-D-16-0180.1.

Holton, J. R., and G. H. Hakim, 2013: An Introduction to Dynamic Meteorology. 5th ed. Academic Press, 532 pp.

Hurrell, J. W., Y. Kushnir, G. Ottersen, and M. Visbeck, 2003: The North Atlantic Oscillation: Climate Significance and Environmental Impact. Geophys. Monogr., Vol. 134, Amer. Geophys. Union, 279 pp.

Iacono, M. J., J. S. Delamere, E. J. Mlawer, M. W. Shephard, S. A. Clough, and W. D. Collins, 2008: Radiative forcing by longlived greenhouse gases: Calculations with the AER radiative transfer models. J. Geophys. Res., 113, D13103, https://doi.org/ 10.1029/2008JD009944.

Kutzbach, J. E., 1967: Empirical eigenvectors of sea-level pressure, surface temperature and precipitation complexes over North America. J. Appl. Meteor., 6, 791-802, https://doi.org/10.1175/ 1520-0450(1967)006<0791:EEOSLP > 2.0.CO;2.

Lee, S., T. Gong, S. B. Feldstein, J. A. Screen, and I. Simmonds, 2017: Revisiting the cause of the 1989-2009 Arctic surface warming using the surface energy budget: Downward infrared radiation dominates the surface fluxes. Geophys. Res. Lett., 44, 10 654-10 661, https://doi.org/10.1002/2017GL075375.

Lesins, G., T. J. Duck, and J. R. Drummond, 2012: Surface energy balance framework for Arctic amplification of climate change. J. Climate, 25, 8277-8288, https://doi.org/10.1175/ JCLI-D-11-00711.1.

Lu, J., and M. Cai, 2009: Seasonality of polar surface warming amplification in climate simulations. Geophys. Res. Lett., 36, L16704, https://doi.org/10.1029/2009GL040133.

Luo, B., D. Luo, L. Wu, L. Zhong, and I. Simmonds, 2017: Atmospheric circulation patterns which promote winter Arctic sea ice decline. Environ. Res. Lett., 12, 054017, https://doi.org/ 10.1088/1748-9326/aa69d0.

, L. Wu, D. Luo, A. Dai, and I. Simmonds, 2019: The winter midlatitude-Arctic interaction: Effects of North Atlantic SST and high-latitude blocking on Arctic Sea ice and Eurasian cooling. Climate Dyn., 52, 2981-3004, https://doi.org/10.1007/ s00382-018-4301-5.

Luo, D., A. R. Lupo, and H. Wan, 2007: Dynamics of eddy-driven low-frequency dipole modes. Part I: A simple model of North Atlantic Oscillations. J. Atmos. Sci., 64, 3-28, https://doi.org/ 10.1175/JAS3818.1.

Mlawer, E. J., S. J. Taubman, P. D. Brown, M. J. Iacono, and S. A. Clough, 1997: Radiative transfer for inhomogeneous atmospheres: RRTM, a validated correlated-k model for the longwave.J. Geophys. Res., 102, 16 663-16 682, https://doi.org/ 10.1029/97JD00237.

Namias, J., 1953: Thirty-Day Forecasting: A Review of a Ten-Year Experiment. Meteor. Monogr., Vol. 2, Amer. Meteor. Soc., $83 \mathrm{pp}$.

Polyakov, I. V., and Coauthors, 2002: Observationally based assessment of polar amplification of global warming. Geophys. Res. Lett., 29, 1878, https://doi.org/10.1029/2001GL011111.

Prenni, A. J., and Coauthors, 2007: Can ice-nucleating aerosols affect Arctic seasonal climate? Bull. Amer. Meteor. Soc., 88, 541-550, https://doi.org/10.1175/BAMS-88-4-541.

Rivière, G., and I. Orlanski, 2007: Characteristics of the Atlantic storm-track eddy activity and its relation with the North Atlantic Oscillation. J. Atmos. Sci., 64, 241-266, https:// doi.org/10.1175/JAS3850.1.

Rogers, J. C., and H. van Loon, 1979: The seesaw in winter temperatures between Greenland and northern Europe. Part II: Some oceanic and atmospheric effects in middle and high latitudes. Mon. Wea. Rev., 107, 509-519, https://doi.org/10.1175/ 1520-0493(1979)107<0509:TSIWTB >2.0.CO;2.

Schröder, M., M. Lockhoff, J. M. Forsythe, H. Q. Cronk, T. H. Vonder Haar, and R. Bennartz, 2016: The GEWEX water vapor assessment: Results from intercomparison, trend, and homogeneity analysis of total column water vapor. J. Appl. Meteor. Climatol., 55, 1633-1649, https://doi.org/10.1175/ JAMC-D-15-0304.1.

Seo, K. H., H. J. Lee, and D. M. Frierson, 2016: Unraveling the teleconnection mechanisms that induce wintertime temperature anomalies over the Northern Hemisphere continents in 
response to the MJO. J. Atmos. Sci., 73, 3557-3571, https:// doi.org/10.1175/JAS-D-16-0036.1.

Serreze, M. C., and J. A. Francis, 2006: The Arctic amplification debate. Climatic Change, 76, 241-264, https://doi.org/10.1007/ s10584-005-9017-y.

Simmons, A. J., and D. M. Burridge, 1981: An energy and angular-momentum conserving vertical finite-difference scheme and hybrid vertical coordinates. Mon. Wea. Rev., 109, 758-766, https://doi.org/10.1175/1520-0493(1981)109<0758: AEAAMC $>2.0 . \mathrm{CO} ; 2$

Teisserenc de Bort, L. P., 1883: Etude sur l'hiver de 1879-80 et recherches sur l'influence de la position des grands centres d'action de l'atmosphère dans les hivers anormaux. Ann. Soc. Meteor. France, 31, 70-79.

Thompson, D. W., and J. M. Wallace, 2000: Annular modes in the extratropical circulation. Part I: Month-to-month variability. J. Climate, 13, 1000-1016, https://doi.org/10.1175/ 1520-0442(2000)013<1000:AMITEC > 2.0.CO;2.

Trenberth, K. E., J. T. Fasullo, and J. Mackaro, 2011: Atmospheric moisture transports from ocean to land and global energy flows in reanalyses. J. Climate, 24, 4907-4924, https://doi.org/ 10.1175/2011JCLI4171.1.

Trigo, R. M., T. J. Osborn, and J. M. Corte-Real, 2002: The North Atlantic Oscillation influence on Europe: Climate impacts and associated physical mechanisms. Climate Res., 20, 9-17, https://doi.org/10.3354/cr020009.

Vallis, G. K., E. P. Gerber, P. J. Kushner, and B. A. Cash, 2004: A mechanism and simple dynamical model of the North Atlantic Oscillation and annular modes. J. Atmos. Sci., 61, 264-280, https://doi.org/10.1175/1520-0469(2004)061<0264: amasdm $>2.0 . \operatorname{co} ; 2$.

van Loon, H., and J. C. Rogers, 1978: The seesaw in winter temperatures between Greenland and northern Europe. Part I: General description. Mon. Wea. Rev., 106, 296-310, https:// doi.org/10.1175/1520-0493(1978)106<0296:TSIWTB >2.0.CO;2.

Walker, G. T., and E. W. Bliss, 1932: World weather V. Mem. Roy. Meteor. Soc., 4, 53-84.

Wallace, J. M., and D. S. Gutzler, 1981: Teleconnections in the geopotential height field during the Northern Hemisphere winter. Mon. Wea. Rev., 109, 784-812, https://doi.org/10.1175/ 1520-0493(1981)109<0784:TITGHF $>2.0$. CO;2.

Watanabe, M., 2004: Asian jet waveguide and a downstream extension of the North Atlantic Oscillation. J. Climate, 17, 46744691, https://doi.org/10.1175/JCLI-3228.1.

Woollings, T., B. Hoskins, M. Blackburn and P. Berrisford, 2008: A new Rossby wave-breaking interpretation of the North Atlantic Oscillation. J. Atmos. Sci., 65, 609-626, https://doi.org/ 10.1175/2007JAS2347.1. 